\section{La cultura como investidura, la historia como subjetividad}

María Cecilia Guarás ${ }^{(1)}$

\begin{abstract}
Resumen: Este artículo busca reflexionar sobre la construcción de la narrativa vestimentaria personal, a partir de la reconstrucción de la historia familiar heredada. Paralelizar el recuerdo y el material tangible poniéndolos en diálogo en un contexto diferente al del hecho en sí, actualizado a través de un receptor contemporáneo. Se busca, a su vez, reflexionar sobre la superposición de las temporalidades que se encarnan en memorias y materialidades, escritas en una línea de tiempo y contada a través de relatos escritos, matéricos o hablados. Esta historia escuchada en los relatos, leída en las cartas y observada en las fotografías, se transforma en una investidura que abraza al receptor dotándolo de significado, conteniéndolo, vistiéndolo y componiéndolo más allá de su contemporaneidad. A partir de esta conceptualización se busca analizar la práctica vestimentaria como acto simbólico que trae a un tiempo presente, una herencia cultural que se resignifica de generación en generación. Se pretende analizar el concepto de historia/relato como subjetividad reflexionando sobre la reconstrucción simbólica de lo comprendido como cultura familiar. A partir de relatos, fotografías y objetos de uso cotidiano ya apartados de quienes los poseyeron con anterioridad, profundizar sobre la reconstrucción emocional de la historia contada de nuestros antepasados, como quien elige cada día de su guardarropas una prenda cada día, en este artículo se retomará el eco de algunas historias que han subsistido varias generaciones. Este artículo se construye a partir del desarrollo de "Herencia" una cápsula upcycled de indumentaria realizada por quien lo escribe, en un viaje en tiempo y espacio hacia los antepasados familiares.
\end{abstract}

Palabras clave: Cultura - vestido - herencia - moda - relatos -fotografía - reciclado - memoria - textiles - signo.

[Resúmenes en inglés y portugués en las páginas 127-128]

(1) Formación académica como Diseñadora de Indumentaria y Textil, especializada en Sociología del Diseño por la Universidad de Buenos Aires. Investiga sobre el diseño como campo de evolución hacia la transdisciplina y la traducción de fenómenos de tendencias macro-micro sociales con enfoque heurístico en el grupo Prospectivas en red (UBA). Desarrolló su experiencia en diversas marcas trabajando para Argentina, Perú y China.

Actualmente es docente de diseño textil en UADE y trabaja como consultora sobre Economía Circular para Red Pacto Mundial (UN) mientras desarrolla procesos de diseño y gestión de estéticas para diversas marcas de moda de Buenos Aires. 
Docente Universitaria - UADE (2009-2019). Diseño y Consultoría en gestión, materiales y procesos del vestir- FreeLance (2018- actual). Gerente Regional de Desarrollo de Producto - Lee - VF Corporation (2011-2017).

\section{Introducción}

Regresar a una casa que fue construida 100 años atrás es, sin dudas, una experiencia que atraviesa el cuerpo. Los sentidos se abren para descubrir nuevas grietas, aromas, paisajes y colores. La memoria reconstruye una historia vívida, que habita la piel del visitante. La entrada de la luz empujando vidrios, sin tocarlos pero envolviéndolos en un abrazo refractario, es una de las imágenes que se quedan en las retinas. Pero esto no sucede tan solo por lo visto en sí, sino porque como suceso encuentra un pasado con un tiempo presente. El sol está ahí brillando ahora, por fuera de las ventanas, metiéndose en un esfuerzo exitoso, hacia adentro de la casa.

$\mathrm{Al}$ abrir una hendija polvorienta, algunas micro partículas se desprenden y vuelan. Entra, desde afuera, una brisa de aire. Hay cortinas que son empujadas por este viento y puedo descubrir, en un vértice inferior del género, una insignia bordada: la inicial del apellido familiar. A lo largo de un centenar de años han habitado esa casa diferentes miembros de mi familia materna. Mis bisabuelos fueron quienes estrenaron las instalaciones al llegar como inmigrantes españoles, con algunos sueños atrapados en las palmas de las manos, y otros hechos añicos que simplemente han quedado atrás.

Se mudan, se cruzan, se reproducen. La cultura Ibérica comienza a mezclarse con su descendencia nacida en Argentina. En la casa se hablaba francés, cuando se pregunta al respecto en un intento ambicioso por reconstruir la historia. A pesar de ser hispánicos, ibéricos, argentinos y rioplatenses, en la casa hablaban la lengua romance. Entonces la narrativa comienza a resultar compleja y surge el interrogante: ¿Eran en esta familia hispánicos, ibéricos, argentinos y rioplatenses? Inmediatamente la respuesta es ambigua, es posible responder sí y no, se construyeron multiculturas y un sentido de pertenencia que se volvió una práctica y una búsqueda que los invistió en un nuevo significado, comprendido solamente a través de las particularidades del desenlace de la historia familiar y sus respectivos entramados vinculares, tejidos en un tiempo que se extiende hasta hoy y que existirá mañana en la descendencia futura.

Este escrito se traduce en una búsqueda de tipo ensayística, entrelazando un marco teórico de tipo sociológico con el campo de lo subjetivo, a través de la experiencia individual de quien lo escribe, de sentirse hereditaria de un cruce cultural complejo.

Heritage es una cápsula de piezas únicas realizadas a mano a través de la metodología Upcycling. Las cortinas, visillos y cortinados de una casa de 100 años, fueron el punto de partida para el desenlace de la nueva narrativa que se crea a partir de la unión simbólica entre la herencia de la práctica del vestir dentro del marco de una cultura familiar determinada, la temporalidad y la anti-moda como negación de lo impermanente. 


\section{El vestido}

Una de las acepciones del término moda alude a la etimología de la palabra, proveniente del latín modo. A su vez, lo que en español practicamos a través de la conceptualización del modo es una serie de usos y costumbres que se distinguen en la forma de realizarse, por una sutileza apropiada por parte del sujeto que ejerce una acción. Esta apropiación de un modo determinado es un concepto complejo y dinámico, que se comprende a través del habitus del practicante (Bordieu, 1990).

Vestirse, por ejemplo, es una práctica que se relaciona con un modo determinado de hacerlo, pero este modo cambia según donde esté situado el cuerpo que ejerce la situación. Con esto se pretende bocetar la idea de que cualquier acción que ejerza un ser social va a estar atravesada por una temporalidad y un contexto que lo rodea y lo dota de significado. La práctica del vestir ha estado asociada a cuestiones elementales de los animales sociales desde antaño, pero hace muchos años que también se ha comprendido como un acto complejo de carácter simbólico. Alejado en este caso de cuestiones tipológicas y en términos teóricos, el vestido es la forma en que viste una sociedad, en una época determinada (Wilson, 1985).

En un artículo de la década del cincuenta y para referirse a la oleada de locura colectiva que se apoderó un verano de las calles de París, el poeta francés Jean Cocteau escribió en un artículo de revista sobre la moda como una epidemia vertiginosa que obliga a personas diferentes y antagónicas a obedecer todas un mismo orden misterioso, a someterse a nuevos hábitos que trastocan sus viejas formas de vida, hasta el momento en que llega un nuevo orden y les obliga a dar la vuelta una vez más (1956). Esta oportuna referencia alude a la intrínseca relación que se establece entre el modo y la práctica, facilitada por el fenómeno de la moda que lo distribuye de modo invisible y colectivo a través de prendas del vestir. Esta proliferación habitual conlleva a la condensación en masa de un gusto determinado, que es legitimado por la institución invisible de la Moda (Bordieu, 1990).

Ahora bien, otra de las aristas investidas por el alcance de un modo es la práctica cultural. Todos nacemos dentro del marco de una cultura determinada por su geografía y su historia, y dotada de significado a través de las prácticas simbólicas que un grupo de personas que se desarrollan en dicho contexto. Dentro de las mismas se encuentra el vestir como una de aquellas en las que todos los grupos sociales ejercen en cualquier parte de la historia y de la Tierra habitada por humanos, pero que en todos los casos proporciona diferencias al momento de la práctica.

A su vez, es una de las que apela a la complejidad de la construcción de estima de cada individuo por la íntima relación que establece entre el cuerpo a través del cual el mismo se materializa con su contexto.

\section{Moda, modo y modernidad}

La modernidad se narra en el entrecruzamiento de una temporalidad lineal progresiva que incluye progreso, disrupción, innovación y una temporalidad cíclica, cuya dinámica 
mantiene intrínsecas relaciones con el sistema de la moda no por retrógrada sino por envolvente. Se reinventa a sí misma en una ilusoria narrativa novedosa.

La moda retoma diversos símbolos culturales despojándose de significado, y así en su consciente y voluntaria superficialidad le hace llegar al emisor, que puede vestir cualquier signo sin formar parte de su relato intrínseco (Veneziani, 2014). Así es como la moda y la cultura dialogan sin ahondar en su relación hasta que llega la sociología para vincularlas de modo íntimo no a priori como disciplinas sino adquiriendo significado solamente a través del portador en su contexto. Ahora bien, dentro del seno de la cultura familiar, esto sucede con el paso del tiempo entre generaciones. La apropiación por parte de un individuo, de cada signo heredado que retoma del pasado, es semejante a una práctica de la moda. Si bien el objeto puede conservar su significado emocional para el usuario, así también lo hace la moda que apela constantemente a la formación de estima del receptor. Algo vacío de significado no quiere decir, en este caso, que no posee ninguno sino que la reconstrucción constante de lo que va significando a lo largo del tiempo está atravesada por la subjetividad de quien se está construyendo a sí mismo.

No fue tomado como ejemplo arbitrariamente un objeto de la casa o un textil. Se buscaron aquellos que en su exquisitez llevaban a un lugar al que uno quisiera ir como acompañantes en la búsqueda de identidad familiar, porque tenía bordado el apellido de la familia, una foto con una reseña escrita que se reconstruye para formar parte de la narrativa que se estaba desarrollando. Estos esfuerzos que se ponen en la búsqueda, están atravesados por cómo se construyó y cómo se desarrolló la propia práctica vestimentaria.

La moda es muerte a la vez que reconstrucción, y es a través de esta lógica que se reconstruye la propia historia familiar y se recicla a través de nuevas significaciones y formas que se construyen, para evitar que muera. Porque si ella muere, muere el espíritu familiar también.

Puede que no sea casualidad, pero la moda es contemporánea con la irrupción del museo. Al igual que el sistema museográfico, la moda acaba tendiendo a la yuxtaposición de formas pasadas y su constante exposición, manifestación y resignificación. Su sistema es inexplicable por fuera de esta relación que dicho fenómeno mantiene con el pasar del tiempo y la escritura de la historia.

Ambos sistemas funcionan hoy como legitimadores de cuestiones estéticas y de gusto y mantienen cierto aura de credibilidad, dotando de verdad a aquello que incluyen a través de sus instituciones.

Todo esto que vamos aceptando e incluso construyendo conforme pasa el tiempo y crecemos, no es intrínseco a nuestra existencia natural sino que responde a nuestra configuración social. De hecho, lo primero que hacen cuando venimos al mundo es abrazarnos en un manto textil, y de las primeras reacciones que tenemos al respecto es llorar; tan pronto como ganamos fuerza en nuestros brazos y ejercemos movimientos autónomos, arrancamos la ropa con la que nos visten.

El vestido es cualquier cuerpo adornado dentro de una cultura. El niño sufre la práctica de ser vestido y se resiste. Aunque con el pasar del tiempo va a adoptar esta práctica cultural aprehendida, hay cierta intuición del niño que nace que lo hace obrar de acuerdo con las leyes de su naturaleza biológica y no social. No lo hace solo como un acto de repudio o rebeldía sino que a través de esta resistencia pretende hacer preponderar su individualidad 
por sobre la influencia externa, la apropiación por sobre la imposición. En esta lucha en la que gana su existencia como ser social vestido, arranca de sí formas pasadas que luego re adopta resignificándolas. Y llamamos formas pasadas al vestido que pretende envolver su cuerpo, porque el mismo ya trae consigo una serie de significaciones que son simbólicamente relevantes dentro de lo que se construye como cultura familiar. Dentro de esas formas pasadas, hay elementos constitutivos que son pasajeros y otros elementos que son de permanencia.

A los elementos pasajeros los conocemos como moda, a los de permanencia como modo, que en su correlación y desarrollo conforman una práctica cultural.

\section{La relación emocional con el signo del pasado}

Poseer es estar unido al objeto poseído en forma de apropiación; desear poseer es desear estar unido a un objeto en esta relación. El deseo de tener es lo mismo que el deseo de ser. No solo quiero la chaqueta de mi madre, quiero unirme a ella para formar una sola entidad. Por lo tanto, estoy compuesto simultáneamente por el yo y el no yo: la chaqueta, y así me convierto en la persona es de alguna manera el propósito del objeto que posee (Sartre, 1943).

Cuando inicialmente retomamos formas del pasado, sentimos que existe una intención selectiva de nuestra parte que es autónoma a la forma deseada. Sin embargo, apropiarse de esas manifestaciones y signos dota al signo tomado de un simbolismo, que es lo que tomamos luego para trazar la narrativa, y que la dotará de sentido. La línea espacio temporal que nos atraviesa también nos construye.

Cuando elegimos una prenda que consideramos única, en este contexto una de carácter vintage, nos la apropiamos creyendo que no tiene ningún otro propósito posible que el de ser usada. Pero lo que realmente genera sentido en esta dinámica, es el concepto de la posesión como creación continua, lógica a través de la cual dialoga el sistema vestimentario con la narrativa histórica.

Para el autor francés Sartre (1943), el acto de adquisición de un objeto equivale a un acto de creación. De hecho, el usuario da sentido a la prenda elegida: la contextualiza y la actualiza en medio de otras prendas: la chaqueta de mi madre no es una chaqueta, sino que es la forma en que la uso, la forma en que interactúo con ella. En este proceso de personalización de la prenda se va trazando una nueva narrativa en la cual el objeto no puede tener sentido sin mi acto de uso, sin una relación de apropiación, y allí donde lo dotó de identidad, construyó al unísono la propia. El autor sugiere que la totalidad de mis posesiones refleja la totalidad de mi ser y que soy lo que tengo. La posmodernidad ha retomado este criterio para segmentar a los grupos sociales, estandarizando sus identidades a través de sus posesiones.

A través de historias familiares se comparte el relato que dentro de la casa los integrantes de la familia se comunicaban en una lengua que no era la nativa, gracias a esto comprendí que en parte esta forma de comunicarse tenía una significación social que respondía a la lógica de imitar lo deseado y diferenciarse de lo que no querían ser. La lengua escogida, la 
apropiada, pertenecía al universo simbólico del vínculo emocional que mantenían con ese código de lenguaje, que en su caso los trasladaba a una época dorada pasada donde habían vivido temporalmente para estudiar y nutrirse, para configurar su modo de ser o estar en el mundo. De ese modo se observa una apropiación del lenguaje por parte del hablante y un acto de locución que establece un presente, que actualiza el uso del lenguaje en un contexto actual.

Con el sistema del vestir sucede algo semejante, y la moda que mata al modo, suele atentar contra las significaciones intrínsecas, pero coopera en la producción simbólica. El deseo se refiere al mismo tiempo al deseo de ser y al deseo de tener, y aunque son distintos son inseparables en la vida cotidiana. El primero está relacionado con el para sí, cuando el deseo de tener apunta al para sí en, en y a través del mundo. Las opciones de consumo y apropiación reflejan, por lo tanto, una determinada forma de estar en el mundo. La compra de una prenda entre otras no es insignificante, traduciendo simbólicamente a nuestra percepción una determinada manera que el ser tiene de darse en su contexto. En lugar de un simple receptor pasivo, el consumidor se convertiría en un productor de nuevos significados a partir de un repertorio establecido de productos.

En la construcción de una cultura familiar, nos encontramos ante la posibilidad de utilizar de una nueva forma el capital preestablecido, que es herencia. Muchos objetos cotidianos ordinarios pueden haber sido resignificados y vaciados de su significado original a través de nuestro uso, e incluso no siempre podemos saberlo.

En casos extremos esta lógica suele relacionarse con prácticas vestimentarias subculturales que retoman formas del pasado para insertarlas en contextos impensados, pero fuera de este extremo, lo hacemos constantemente cuando estamos reconfigurando nuestras propias identidades a través de la vestimenta heredada. Es así cómo se genera una yuxtaposición cultural, temporal e incluso de género en la actualización propuesta para la cual se utilizan prendas vintage o resignificadas pertenecientes a la familia en décadas pasadas.

\section{Una narrativa codificada}

A partir del modelo comunicacional del lingüista Roman Jakobson (1984), el antropólogo Grant McCracken se pregunta hasta qué punto el sistema vestimentario es comparable con el lenguaje y, más precisamente, al código lingüístico. Al realizar un experimento con un panel de participantes que consiste en medir cómo perciben la comunicación frente a diapositivas con prendas de vestir, observa tres tipos de respuestas incluida una interpretación cierta, incierta o totalmente imposible. El primer tipo de reacción se refiere a una interpretación determinada e instantánea del mensaje de la indumentaria, que en última instancia corresponde a ciertos estándares preestablecidos de tipo sociales. Si bien la transparencia del mensaje tiene el mérito de ser clara, no es suficiente que el antropólogo describa el mensaje codificado a través de la presencia de prendas del vestir como lenguaje. La interpretación, pecando por su falta de linealidad, de lectura de sentido, no sigue una lógica sintagmática, para simplemente considerar el mensaje como un todo comparable a un tipo social. Ante la presencia de prendas con apariencias más incoherentes, los parti- 
cipantes ya no parecen justificar una lectura perfecta del mensaje, a lo que el observador participante llama como incierto. Ante la presencia de una gramática vestimentaria aún menos legible, el autor finalmente observa a ciertos participantes en una situación en la que es imposible leer, ya que la ropa definitivamente está demasiado lejos de las normas de vestimenta preestablecidas.

Esta última categoría permite a McCracken llegar a la hipótesis de que cuanto más imite el mensaje de la indumentaria al del lenguaje y su libertad combinatoria, menos será entendido. Esto es para él una prueba de que la ropa no puede constituir un lenguaje, sino a lo sumo un código restringido por la ausencia de un principio combinatorio, es decir, por la necesaria prefabricación de un mensaje similar a los tipos sociales identificados.

Pero tal como sugiere el lingüista Jakobson, para comprender un mensaje es preciso decodificar la intención significativa. Si el código se altera se genera ruido en la comunicación, y el lenguaje resulta ilegible para un receptor que no conozca la intención del emisor.

A la moda le seduce jugar con la alteración de estos códigos y lo hace a menudo a través de lo que se mencionó anteriormente como yuxtaposición, proceso mediante el cual se aproximan sino amontonan signos retomados de diferentes contextos, momentos o circunstancias. A través de la moda asociamos ciertos modos relacionado a este fenómeno como el lenguaje, los gestos y los complementos ya que vacía de significado el referente inicial y lo actualiza para hacerlo significar algo diferente, a menudo relacionado con el habitus y la posición social. La moda rechaza el cambio a menos que ella lo imponga, a través de esta dinámica establecida por el sistema sobre el cual se rige establece códigos que legitima y se proliferan a partir de su amplio espectro comunicacional.

Aquellos signos que queden por fuera de dicho sistema, no serán decodificables para otro más que el emisor y su círculo inmediato con quien comparte el código, o bien será marginado al terreno de la anti-moda.

\section{La artesanía de atravesar el tiempo}

El término upcycling, del idioma inglés, hace alusión a la metodología mediante la cual una prenda u objeto es retomado para su reciclaje pero también para la transformación de su funcionalidad inicial. A lo largo de este proceso, la prenda va a alejarse de su significación fundacional para pasar a formar parte de una nueva narrativa, trazada a partir de su actualización. En la actualidad este concepto resuena a menudo en el contexto de las prácticas sostenibles de la producción vestimentaria, ya que el impacto ambiental negativo que genera es significativamente menor al de la producción de indumentaria en grandes volúmenes.

El proyecto Heritage, que es a través del cual surgen las reflexiones aquí compartidas, se hizo a partir de la técnica upcycling, convirtiendo viejas cortinas que colgaban de las ventanas de una casa de cien años de antigüedad en la que vivió gran parte de la familia materna de quien escribe, a lo largo del tiempo.

$\mathrm{Al}$ retomar los géneros textiles de las tipologías mencionadas para convertirlos en prendas de vestir reconfiguradas, hubo cierta revelación de la yuxtaposición de temporalidades 
sumada a la simbología que aquellos guardaban en relación con la construcción de la cultura familiar.

Algunas más ligeras, livianas y otras más pesadas con tramas cerradas, las cortinas dejaban pasar solo una parte de la luz que entraba desde afuera. Si la luz entraba completa, entonces el reflejo era producto de la relación de esa porción de vidrio, con ese género.

El proceso de deconstrucción y reconstrucción, completamente manual, facilitó la conexión carnal de un ser con una porción simbólica de su historia, generando un nuevo código posible en la práctica de vestir, que incluye la investidura como posesión identitaria.

\section{Conclusiones}

Para poder trazar este escrito un pequeño recorrido ensayístico sobre las reflexiones que surgieron a partir de la observación sobre la configuración de una historia familiar materna, fueron retomadas ciertas formas del pasado que fueron resignificadas.

Las cortinas fueron seleccionadas de entre una amplia variedad de materialidades textiles puesto que fueron consideradas un velo entre la intimidad interior de un hogar en relación con el exterior. Aquello que las mismas dejan entrever y sus juegos ondulantes con la posibilidad de luz u oscuridad, me permitieron profundizar sobre una nueva conciencia de que es lo que realmente había ingresado a la casa de 100 años de antigüedad.

Mientras observo, la escritora Didion (2015) se me viene a la mente a través de unas palabras que alguna vez escuche, que decían algo como que la persona forma parte del paisaje que la rodea, reflexión a la cual agrego mientras reconstruyo la frase en mi mente, que la persona forma también al paisaje que habita. Esta reciprocidad simbólica, socialmente humana como pocos fenómenos que recuerdo, habilita la codificación de la narrativa identitaria de la práctica vestimentaria y sus modos asociados, que trazamos dentro del seno de nuestra familia, escribiendo una historia única que dialoga con un contexto histórico, dinámico y complejo. Una casa de 100 años. Un montón de tesoros, la sombra de los fantasmas. Sillas polvorientas, cuerdas colgantes. Una historia escrita detrás de las puertas de un edificio antiguo. En donde el sol de vez en cuando, va de visita (Guaras, 2020).

\section{Bibliografía}

Baudelaire, C. (1863). Le peintre de la vie Moderne. Paris: Collection Litteratura.com. Baudrillard, J. (1976). Symbolic Exchange and Death. Estados Unidos: SAGE Publications. Bauman, Z. (1994). Pensando sociológicamente. Extracto de la Introducción: Sociología ¿Para qué? Buenos Aires: Nueva Visión.

Bourdieu, P. (1990). Sociología y cultura. Traducción de Matha Pou. México DF: Grijalbo.

Bourdieu, P. (1971). Elementos de una teoría sociológica de la percepción artística. Buenos Aires: Nueva Visión.

Didion, J. (2015). El año del pensamiento mágico. Estados Unidos: Literatura Random House. 
Bourdieu, P. y Delsaut,Y. (1975). Le couturier et sa griffe: contribution à une théorie de la magie. In: Actes de la recherche en sciences sociales. Hiérarchie sociale des objets. 1, 7-34. Entwistle, J. (2002). El cuerpo y la moda, una visión sociológica. Barcelona: Paidós. Flügel, J. (1930). The psychology of clothes (1930). New York: AMS press.

García Canclini, N. (2001). Las culturas híbridas en tiempos globalizados en: Culturas Híbridas. Buenos Aires: Paidós.

García Martinez, J. (2017). El habitus. Una revisión analítica. Córdoba: Revista Internacional de Sociología.

González Villarruel, A. (2010). La vida social de los objetos etnográficos y su desalmada mercantilización. México DF: Alteridades.

Guaras, M. C. (2020). Campaña de comunicación Heritage. Buenos Aires.

Habermas, J. (1989) El discurso filosófico de la modernidad. Madrid: Taurus.

Heidegger, M. (1927). Ser y tiempo. 2da, Parte. trad. por Jorge Eduardo Rivera. Santiago de Chile: Editorial Universitaria.

Jakobson, R. (1984). Lingüística y poética. Ensayos de lingüística general. Barcelona: Ariel. Polhemus, T. (1978). Fashion \& Anti-Fashion. Londres: Thames and Hudson.

Sartre, J. (1993). Being and nothingness. Washington: Square Press.

Tusón-Valls, J. (2003). Introducción al lenguaje. Barcelona: Ariel.

Veneziani, M. (2014). Escritos en la Facultad Nº5. Buenos Aires: Universidad de Palermo. Wilson, E. (1985). Adorned in Dreams: Fashion and Modernity. Nueva York: I.B. Tauris.

\begin{abstract}
This article seeks to reflect on the construction of the personal clothing narrative, based on the reconstruction of the inherited family history. Parallelize the memory and the tangible material by putting them in dialogue in a different context from the event itself, updated through a contemporary receiver. It seeks, in turn, to reflect on the superposition of temporalities that are embodied in memories and materialities, written in a timeline and told through written, material or spoken stories. This story heard in the stories, read in the letters and observed in the photographs, is transformed into an investiture that embraces the recipient, endowing him with meaning, containing him, dressing him and composing him beyond his contemporaneity. Based on this conceptualization, we seek to analyze clothing practice as a symbolic act that brings to a present time, a cultural heritage that is resignified from generation to generation. It is intended to analyze the concept of history / story as subjectivity reflecting on the symbolic reconstruction of what is understood as family culture. From stories, photographs and objects of daily use already separated from those who previously owned them, to delve into the emotional reconstruction of the story told of our ancestors, as someone who chooses a garment every day from their wardrobes, in this article will take up the echo of some stories that have survived for several generations. This article is built from the development of "Herencia", an upcycled capsule of clothing made by the writer, on a journey in time and space towards family ancestors.
\end{abstract}


Keywords: Culture - dress - heritage - fashion - stories - photography - recycling - memory - textiles - sign.

Resumo: Este artigo busca refletir sobre a construção da narrativa do vestuário pessoal, a partir da reconstrução da história familiar herdada. Paralelizar a memória e o material tangível, colocando-os em diálogo em um contexto diferente do próprio evento, atualizado por meio de um receptor contemporâneo. Busca, por sua vez, refletir sobre a superposição de temporalidades que se materializam em memórias e materialidades, escritas em uma linha do tempo e contadas por meio de histórias escritas, materiais ou faladas. Essa história ouvida nas histórias, lida nas cartas e observada nas fotos, se transforma em uma investidura que abraça o destinatário, dotando-o de sentido, contendo-o, vestindo-o e compondo-o para além de sua contemporaneidade. A partir dessa conceituação, buscamos analisar a prática do vestuário como um ato simbólico que traz para a atualidade uma herança cultural que se redefine de geração em geração. Pretende-se analisar o conceito de história / história como subjetividade refletindo na reconstrução simbólica do que se entende por cultura familiar. A partir de histórias, fotografias e objetos de uso cotidiano já separados de quem os possuía anteriormente, para mergulhar na reconstrução emocional da história contada de nossos ancestrais, como quem escolhe uma vestimenta todos os dias de seus guarda-roupas, neste artigo vai retomar o eco de algumas histórias que sobreviveram por várias gerações. Este artigo é construído a partir do desenvolvimento de "Herencia", uma cápsula reciclada de roupa feita pelo escritor, em uma viagem no tempo e no espaço em direção aos ancestrais familiares.

Palavras chave: Cultura - vestido - patrimônio - moda - histórias - fotografia - reciclagem - memória - têxteis - signo.

[Las traducciones de los abstracts fueron supervisadas por el autor de cada artículo] 